\title{
Knowledge of Prostate Gland Hvnertronhv. Associated I rinary Elimination Problems And Health Seeking Practices In Men Aged 50 And Above
}

\author{
Helen Nyamutsamba ${ }^{1}$, Margaret Nkhomo ${ }^{2}$, Mathilda Zvinavashe ${ }^{3}$, \\ Doreen Mukona $^{4}$ \\ ${ }^{1,2,3,4}$ Department Of Nursing Science, University of Zimbabwe College of Health Sciences, Zimbabwe
}

\begin{abstract}
Prostate gland hypertrophy (PGH) has a prevalence of over $50 \%$ in men over 60 years and is associated with a number of urinary elimination problems. However, men delay in seeking treatment for urinary elimination problems despite the availability of reproductive health services. The purpose of the study was to identify the knowledge of $P G H$, practices and urinary elimination problems in men aged 50 and above. A descriptive research design was used on a convenient sample of 50 men aged 50 years and above. Data were collected using interviews and analysed using Microsoft Excel. The majority (92\%) participants did not know the prostate gland and only $36 \%$ had heard about it before. Of the 36\% that had heard about it before $22 \%$ had heard about it from non-medical sources. Twenty percent participants mentioned that PGH is caused by witchcraft while $18 \%$ did not know the causes. The most common symptom of PGH mentioned by $66 \%$ participants was difficulty starting flow of urine. Other symptoms were failure to pass urine (18\%), frequency (10\%) and weakening of stream of urine (10\%). Only 10\% participants admitted that they would seek medical care for urinary elimination problems while $90 \%$ would ignore, use home remedies or consult traditional healers. Majority $88 \%$ participants agreed they would benefit from screening for PGH. Health care providers, especially nurses, need to be trained on management of men's reproductive health issues. Access to men's reproductive health must be improved by subsidising treatment costs, decentralization of services and widespread health education.
\end{abstract}

Keywords: Knowledge, prostate gland, hypertrophy, urinary elimination

\section{Introduction}

Benign prostatic hypertrophy is a serious condition affecting males aged from 60 years onwards. It is characterised by proliferation of smooth muscle and epithelial cells in the prostatic transition zone. Urinary tract problems result from direct bladder outlet obstruction (BOO) from enlarged tissue (static component) and increased smooth muscle tone and resistance within the enlarged gland (dynamic component) occur. Physical presence of BOO results in voiding symptoms. Detrusor over activity, on the other hand contributes to the storage symptoms seen in lower urinary tract symptoms (LUTS). It has been acknowledged that BPH is an underdiagnosed condition that significantly affects the quality of life of many men.[1] It is a common problem in men older than 50 years of age. As many as 14 million men in the United States had lower urinary tract symptoms suggestive of benign prostatic hyperplasia in 2010.[2] According to the Urology Care Foundation (2013) it affects about 50 percent of men between the ages of 51 and 60 and up to 90 percent of men older than 80. [3]

Two theories have been proposed in the development of PGH. The first one is the increased production of estrogen and reduced testosterone levels as men age that result in increased activity of substances promoting prostate cell growth and ultimately benign prostatic hyperplasia. The other theory implicates dihydrotestosterone (DHT), a male hormone that plays a role in prostate development and growth. Older men continue to produce and accumulate high levels of DHT in the prostate even when testosterone levels have dropped thereby encouraging prostate cells to continue to grow.[4]

The gold standard treatment of benign prostatic hypertrophy is transurethral resection of the prostate.[5] However minimally invasive therapies such as holmium laser enucleation of the prostate, transurethral electrovaporization of the prostate and transurethral microwave thermotherapy have been discovered over the past two decades. According to the European Association of Urology guidelines, open prostatectomy, however, is the treatment of choice for large prostate glands more than $80 \mathrm{ml}$ to $100 \mathrm{ml}$ in size.[6]

The prevalence of PGH increases from 25\% among men 40 to 49 years of age to more than $80 \%$ among men 70 to 79 years of age. Although many men with histologic findings of benign prostatic hyperplasia and even anatomically enlarged prostates due to this condition have no symptoms, more than $50 \%$ of men in their 60 s to as many as $90 \%$ of octogenarians present with lower urinary tract symptoms.[7] 
Knowledge Of Prostate Gland Hypertrophy, Associated Urinary Elimination...

A study conducted in Zimbabwe by Karera et al. (2014) revealed a very high prevalence of BPH of 60\%.[8] In Zimbabwe the total cumulative total number of cases of prostate malignancy was 2594 in 2004. Forty-four cases of PGH were reported for Mashonaland East Province in 2004 with the cause being either malignance or benign hypertrophy.[9] Marondera Provincial Hospital had 19 cases in 2002; 25 in 2003 and 34 in 2004 respectively. These statistics infer an increase in the number of patients with urinary elimination problems due to $\mathrm{PGH}$.

Health seeking behaviour, refers to how people seek, obtain, evaluate, categorize and use relevant health-related information to perform desired health behaviours.[10] Good health seeking behaviours are associated with stronger positive health-oriented beliefs and healthier behaviours in general. Elderly men display low health literacy and poor health-seeking behavior. Findings of a study conducted by Bourne et al. (2010) revealed that despite the reported good self-related health status (74.4\%) and high cognitive functionality (94.1\%) of the older men, only $7.9 \%$ sought medical care outside of experiencing illnesses, $37 \%$ of rural participants sought medical care when they were ill compared with $31.9 \%$ of their urban counterparts, only $34 \%$ of participants took the medication as prescribed by a medical doctor and $43 \%$ self-reported being diagnosed with cancers such as prostate and colorectal in the last 6 months.[11] Men delay in seeking treatment for urinary elimination problems despite the availability of reproductive health services. Men seek help and use health services less frequently than women do and their help-seeking practices and health service use are complex issues involving biological, psychological and sociological issues.[12] However, only a few studies have explored whether health service providers are equipped to deal with men's health issues appropriately.[12] The purpose of this study therefore was to identify the knowledge and practices on PGH and its associated urinary elimination problems in men aged 50 years and above.

\section{Methods}

A descriptive research design was used to carry out the study. A convenience sample of 50 men aged from 50 years and above was recruited for the study. The study was conducted at a provincial hospital which is a referral centre for surrounding district hospital and other rural health centres. Permission to carry out the study was obtained from the Medical Research Council of Zimbabwe. Voluntary and informed consent was obtained from each and every participant after a full explanation of the nature of the study including the risks and benefits of the study. Data was collected using a questionnaire by way of face to face interviews. Interviews were held in a private room and each interview lasted about 20 minutes. Data was kept in a lockable cupboard and the researcher had sole access to the data. Data was analysed using Microsoft excel and was presented in tables and text.

\section{Results}

Table 1 presents results of demographic data. Of the participants $44(88 \%)$ were aged from 60 years and above, $43(86 \%)$ were married, $41(82 \%)$ had attained some formal education, $43(86 \%)$ were Christians while $34(68 \%)$ were peasant farmers. Thirty-eight (76\%) participants earned less than USD $\$ 50$ per month and $36(72 \%)$ stayed in rural areas.

Table 1: Demographic characteristics (n-50)

\begin{tabular}{|l|c|}
\hline Age in years & Number (\%) \\
\hline $50-59$ & $6(12)$ \\
\hline $60-69$ & $22(44)$ \\
\hline $70+$ & $22(44)$ \\
\hline Marital status & \\
\hline Married & $43(86)$ \\
\hline Divorced & $7(14)$ \\
\hline Level of education & \\
\hline Never attended school & $9(18)$ \\
\hline Primary level & $41(82)$ \\
\hline Secondary level & $0(00)$ \\
\hline Religion & \\
\hline Christian & $43(86)$ \\
\hline Traditional & $7(14)$ \\
\hline Employment & \\
\hline Employed & $5(10)$ \\
\hline
\end{tabular}


Knowledge Of Prostate Gland Hypertrophy, Associated Urinary Elimination...

\begin{tabular}{|l|c|}
\hline Self-employed & $8(16)$ \\
\hline Pensioner & $3(06)$ \\
\hline Peasant farmer & $34(68)$ \\
\hline Monthly income (USD\$) & \\
\hline Below 50 & $38(76)$ \\
\hline $51-100$ & $0(00)$ \\
\hline $101-200$ & $0(00)$ \\
\hline $201-300$ & $2(04)$ \\
\hline $301-400$ & $4(08)$ \\
\hline $401-500$ & $6(12)$ \\
\hline Place of residence & \\
\hline Urban & $14(28)$ \\
\hline Rural & $36(72)$ \\
\hline Farm & $0(00)$ \\
\hline Mine & $0(00)$ \\
\hline Peri-urban & $0(00)$ \\
\hline
\end{tabular}

Results on knowledge of PGH are presented in Table 2. Forty-two (84\%) participants admitted that they did not know the prostate gland. However $32(64 \%)$ had heard about enlargement of the prostate gland. Only $18(36 \%)$ had had some information on the prostate gland while $31(62 \%)$ thought that PGH is caused by old age. Thirty three (66\%) participants mentioned difficulty starting urine as a manifestation of PGH, $9(18 \%)$ mentioned dribbling at end of urine stream, another $9(18 \%)$ mentioned failure to pass urine, $5(10 \%)$ mentioned a weak stream of urine during micturition while $5(10 \%)$ mentioned passing urine more often than usual. Fortyfour $(88 \%)$ agreed that screening for PGH is important.

Table 2: Knowledge of PGH $(\mathrm{n}=50)$

\begin{tabular}{|l|c|}
\hline Do you know the prostate gland? & Number (\%) \\
\hline Yes & $8(16)$ \\
\hline No & $42(84)$ \\
\hline $\begin{array}{l}\text { Have you ever heard about the } \\
\text { prostate gland? }\end{array}$ & \\
\hline Yes & $18(36)$ \\
\hline No & $32(64)$ \\
\hline Source of information & $7(14)$ \\
\hline Health care provider & $11(22)$ \\
\hline Non-medical source & $32(64)$ \\
\hline Never got information & \\
\hline What causes PGH? & $7(14)$ \\
\hline The will of God & $31(62)$ \\
\hline Old age & $3(06)$ \\
\hline Witchcraft & $9(18)$ \\
\hline Do not know & \\
\hline How does PGH present? & $5(10)$ \\
\hline Passing urine more often & $5(10)$ \\
\hline Weak stream of urine & $9(18)$ \\
\hline Difficulty starting urine & $6(12)$ \\
\hline Dribbling at end of stream & \\
\hline Failure to pass urine & \\
\hline Is screening for PGH beneficial? & \\
\hline Yes & \\
\hline No & \\
\hline & \\
\hline
\end{tabular}


Knowledge Of Prostate Gland Hypertrophy, Associated Urinary Elimination...

Table 3 presents results of practices regarding PGH. Five (10\%) mentioned that they would visit the nearest health care centre if they noticed urinary elimination problems, 7 (14\%) would consult traditional healers, 23 $(46 \%)$ would ignore while $15(30 \%)$ would resort to other solutions such as use of home remedies.

Table 3: Practice regarding urinary problems of PGH $(\mathrm{n}=50)$

\begin{tabular}{|l|c|}
\hline $\begin{array}{l}\text { What do if one notices urinary } \\
\text { problems }\end{array}$ & Number (\%) \\
\hline Go to a health centre & $5(10)$ \\
\hline Consult a traditional healer & $7(14)$ \\
\hline Ignore & $23(46)$ \\
\hline Other & $15(30)$ \\
\hline
\end{tabular}

\section{V. Discussion}

The study population comprised 50 men of which $6(12 \%)$ were aged between 50 and 59 years, 22 (44\%) were aged between 60 and 69 years while $22(44 \%)$ were aged from 70 years and above. According to Brunner and Suddarth (2010), there is a high prevalence of PGH in men aged 50 and above.[13]This might be explained by the relative rise in levels of estrogen and DHT as men age .[4] According to the Urology Care Foundation (2013) PGH affects about 50 percent of men between the ages of 51 and 60.

None of the participants had gone beyond primary level of education. Studies have shown that as the level of education increases, health seeking behaviours of individuals also improve. This might also have contributed to the generally poor health seeking behaviours reported in the study. According to Bourne et al (2013) higher literacy level tends to be associated with better health seeking behaviours.[11] The poor health seeking behaviours could also have been compounded by the socioeconomic status of the participants as majority (68\%), were peasant farmers and most probably relied on a seasonal and erratic income. Majority participants also earned less than $\$ 50$ United States dollars per month. All this combined with the age of the participants was likely to lead to poor health seeking behaviors when one experienced any urinary elimination problems. Majority of the participants (72\%) resided in rural areas. Consequently, $72 \%$ also walked to the nearest health care centre. The study setting was a provincial referral centre for surrounding district hospitals and other rural health care centres. All these factors combined could have resulted in some participants choosing to ignore urinary elimination problems, consult traditional healers or to use home remedies. This is moreso because majority of the participants were unemployed and most likely did not have the money needed to access health services. Though treatment for senior citizens above the age of 65 is free in Zimbabwe, there remain hidden costs of such services as transport to health care centres and medications that will be out of stock, as is often the case, in public hospitals.

\section{Knowledge of PGH}

Only $8 \%$ participants knew what the prostate gland is and only one participant could well describe the anatomy of the prostate gland. This might mean that one might not be able to link urinary elimination problems to the prostate gland and might even ignore symptoms or dismiss them as a normal aging process as symptoms usually appear after 50 years of age. Because of culture, one might also be embarrassed to discuss issues of their private parts and elimination. However 18\% participants had some knowledge of something enlarging in the private parts. Of the $18 \%, 14 \%$ had heard information on PGH from medical personnel while $22 \%$ had had the information from non-medical sources. People are likely to have inaccurate information about PGH when it comes from non-trained individuals and there is a danger of adopting inappropriate health seeking behaviors such as not going for screening and also not seeking medical care in time when one experiences urinary elimination problems. This is supported by the fact that $38 \%$ participants did not know the causes of PGH, attributing it to God's will (14\%) and witchcraft (6\%). Some participants (18\%) admitted that they did not know the causes of PGH.

The most common symptom of PGH mentioned by $66 \%$ participants was difficulty starting flow of urine. Other symptoms mentioned were failure to pass urine (18\%) and weakening of urine stream (10\%). According to American Urological Association (2010), these are some of the symptoms of PGH resulting from bladder outlet obstruction due to enlargement of the prostate.[1]

Majority (88\%), mentioned that they would benefit from screening for PGH. This might mean an increased uptake of screening if services are made more accessible. This, therefore, underscores the importance of nationwide programmes for the reproductive health of men, and accessible health services through heavy subsidization of the cost of health care and decentralization of screening and treatment services. There is also 
Knowledge Of Prostate Gland Hypertrophy, Associated Urinary Elimination...

need to set up culture sensitive men's clinics that deal with unique needs of men. It is also hoped that men will be free and open in a men's clinic to talk about their reproductive health issues without embarrassment. Better collaboration is required across disciplines, to further investigate men's health using both qualitative and quantitative research methods.[12] There is also need to embark on in-service training of health care workers especially nurses as they are the health care workers manning the first points of contact of individuals with the health care system.

\section{Conclusion}

Knowledge of PGH was generally low. Because of this low knowledge, majority participants did not think it was necessary to seek medical help for urinary elimination symptoms of PGH. Health care providers, especially nurses, need to be trained on management of men's reproductive health issues. Access to men's reproductive health must be improved by subsidising treatment costs, decentralization of services and widespread health education.

\section{References}

[1]. American Urological Association. (2010). American Urological Association Guideline. Management of benign prostatic hyperplasia (BPH). Retrieved from http://www.auanet.org/common/pdf/education/clinical-guidance/Benign-ProstaticHyperplasia.pdf on 9/02/2015

[2]. Deters,L.A.(2014)Benign prostatic hypertrophy. Emedicine Retrieved from website. http://emedicine.medscape.com/article/437359overview. on 5/02/2015

[3]. UrologyCareFoundation (2014). BPH: surgical management. Retrieved from www.urologyhealth.org/urology/index.cfm?article $=31$ on $5 / 02 / 2015$

[4]. NationalKidneyandUrologicDiseasesInformationClearingHouse.(2014)Retrievedfrom kidney.niddk.nih.gov/KUDiseases/pubs/prostateenlargement/ on 4/02/2015

[5]. Homma, Y., Gotoh, M., Yokoyama, O., Masumori, N., Kawauchi, A., Yamanishi, T., Ishizuka, O., Seki, N., Kamoto, T., Nagai, A., \& Ozono, S. (2011). Japanese Urological Association: Outline of JUA clinical guidelines for benign prostatic hyperplasia. Int J Urol 18:741-756.

[6]. Oelke, M., Bachmann, A., Descazeaud, A., Emberton, M., Gravas, S., Michel, M.C., N’Dow, J., Nordling, J., \& de la Rosette, J.J. (2012). Guidelines on the Management of Male Lower Urinary Tract Symptoms (LUTS), including Benign Prostatic Obstruction (BPO). Arnhem, The Netherlands: European Association of Urology

[7]. Sarma, A. V., \& Wei, J. T. (2012) Benign Prostatic Hyperplasia and Lower Urinary Tract Symptoms. N Engl J Med 367:248-57.

[8]. Karera, A, Maguranyanga, E.F., Nleya, S., \& Chingarande, G. (2014). The effectiveness of ultrasound in early detection of benign prostatic hypertrophy, a case study of Chitungwiza, Zimbabwe. World Journal of Medical Sciences. 10 (2) 122-128

[9]. Health Information Registry Mashonaland East. (2004). Unpublished Statistics.

[10]. Hirvonen, N., Huotari, M.L., Niemelä, R., \& Korpelainen, R. (2012) Information behavior in stages of exercise behavior change. Journal of the American Society for Information Science and Technology 63:1804-1819.

[11]. Bourne, P. A., Morris, C., Charles, C. A. D., Eldemire-Shearer, D., Maureen D Kerr-Campbell, M. D., \& Crawford, T. V. (2013). Health literacy and health seeking behavior among older men in a middle-income nation

[12]. Smith, J. A., Braunack-Mayer, A., \& Wittert, G. (2006). What do we know about men's help-seeking and health service use? Medical Journal of Australia. 184: 81-83

[13]. Brunner, L.S., \& Suddarth, D.S., (2010). Textbook of Medical-Surgical Nursing (12 ${ }^{\text {th }}$ Ed.) Philadelphia, J.B., Lippincott. 